\title{
Urdimento
}

Revista de Estudos em Artes Cênicas

E-ISSN: 2358.6958

\section{A Invenção de Territorialidades Subversivas a partir das Performances Feministas de Tania Bruguera, Martha Araújo e do coletivo Polvo de Gallina Negra}

Amanda Marques

Christine Greiner

\section{Para citar este artigo:}

MARQUES, Amanda; GREINER, Christine. A Invenção de Territorialidades Subversivas a partir das Performances Feministas de Tania Bruguera, Martha Araújo e do coletivo Polvo de Gallina Negra. Urdimento, Florianópolis, v. 2, n. 38, ago./set. 2020.

DOI: http:/dx.doi.org/10.5965/14145731023820200010

Este artigo passou pelo Plagiarism Detection Software | iThenticate 
A Invenção de Territorialidades Subversivas a partir das Performances Feministas de Tania Bruguera, Martha Araújo e do coletivo Polvo de Gallina Negra

Amanda Marques ${ }^{1}$

Christine Greiner ${ }^{2}$

\title{
Resumo
}

Há uma diferença entre considerar performances como ocorrências que acontecem em um local e reconhece-las como acionadoras de territorialidades. A proposta desta pesquisa foi analisar experiências performativas concebidas em Cuba, Brasil e México que instauraram debates feministas através da subversão de territorialidades dadas a priorie suas relações de poder. O objetivo foi borrar dicotomias hierárquicas entre espaços público e privado, artista e espectador, cena e manifesto político, individualidade e coletividade.

Palavras-chave: Performance. Feminismo. Artistas latino-americanas. Territorialidades. Corpo.

The Invention of Subversive Territorialities according to the Feminist Performances of Tania Bruguera, Martha Araújo and the collective Polvo de Gallina Negra

\begin{abstract}
There is a difference between considering performances as occurrences that happen in one place and recognizing them as triggers of territorialities. The purpose of this research was to analyze performative experiences conceived in Cuba, Brazil and Mexico that established feminist debates through the subversion of territorialities given a priori and their power relations. The objective was to blur hierarchical dichotomies between public and private spaces, artist and spectator, scene and political manifesto, individuality and collectivity.
\end{abstract}

Keywords: Performance. Feminism. Latin American artists. Territorialities. Body.

1 Doutoranda do Programa de Comunicação e Semiótica, Pontifícia Universidade Católica de São Paulo (PUC/SP). Concluiu recentemente o doutorado sanduíche com Bolsa CAPES no Center University of New York, CUNY, na cidade de Nova Iorque. Maarques.amanda@gmail.com

2 Prof. Dra. Livre-Docente integrante do Programa de Comunicação e Semiótica, Pontifícia Universidade Católica de São Paulo (PUC/SP), e da graduação em Artes do Corpo na mesma instituição. Pesquisadora de Produtividade CNPq. christinegreiner@gmail.com 
La invención de las territorialidades subversivas basadas en las representaciones feministas de Tania Bruguera, Martha Araújo y el colectivo Polvo de Gallina Negra

\section{Resumen}

Hay una diferencia entre considerar las actuaciones como ocurrencias que suceden en un lugar y reconocerlas como impulsoras de territorialidades. El propósito de esta investigación fue analizar experiencias performativas concebidas en Cuba, Brasil y México que instigaron debates feministas a través de la subversión de las territorialidades a priori y sus relaciones de poder. El objetivo era difuminar las dicotomías jerárquicas entre espacios públicos y privados, artista y espectador, escena y manifiesto político, individualidad y colectividad.

Palabras clave: Performance. Feminismo. Artistas latinoamericanos. Territorialidades. Cuerpo. 
Desde a chamada pré-história da performance, com as vanguardas artísticas do início do século XX, temas políticos são colocados em questão a partir da ocupação de espaços. Jorge Glusberg (1997) e, em seguida, o pesquisador brasileiro Renato Cohen (1998), elencaram vários exemplos de como a presença do corpo na cidade, fora de palcos e locais destinados à apresentação artística (galerias, museus, etc.) teria um papel fundamental, não apenas para ilustrar debates políticos, mas para propor questões.

Inicialmente, autores como Peggy Phelan (1993) chamaram a atenção para o modo como tais performances lidavam com o que esta autora identificou como uma "ontologia do desparecimento". As performances, especialmente as que aconteciam em espaços públicos, seriam sempre provisórias e impermanentes. Ou seja, ocorriam e imediatamente desapareciam. Esta aptidão para o desaparecimento inevitável trazia uma questão política importante relacionada à negação daquilo que já estaria estabilizado como categoria, padrão de comportamento, certeza ideológica e assim por diante. A ação performativa perene clamava pela desestabilização de modelos e hierarquias dadas a priori, valorizando algo que não poderia ser quantificado e que por isso mesmo, teria um valor político e não monetário no sentido capitalista habitual. Mesmo que, alguns anos depois, Rebecca Schneider (2011) tenha criticado esta "ontologia do desaparecimento", discutindo a importância do termo reenactment como a urgência em fazer aparecer e re-ativar questões (políticas) do passado; a leitura de Phelan ainda parece trazer uma vitalidade importante ao debate, na medida em que pensa como o movimento e a presença corporal desestabilizam algumas certezas.

Mais recentemente, Ana Pais (2017) organizou seminários em Lisboa que geraram uma coletânea de ensaios para refletir sobre a performance na esfera pública, traduzindo para a língua portuguesa autores referenciais como Bojana Cvejic e Ana Vujanovic, Claire Bishop e as já mencionadas Phelan e Schneider; além de alguns artistas pesquisadores como a brasileira Eleonora Fabião e o mexicano Guillermo Gómez-Peña.

Mais do que um local público (praça, parque, avenida, etc.), a noção de esfera 
pública consiste na construção de forças, redes comunicativas e empatia. Não basta, portanto, ocupar um local público. É preciso transformá-lo a partir de ações que deixem um traço performativo, como pontuou Judith Butler (1990), a partir dos debates de John Austin (1962) acerca do reconhecimento das palavras como ações.

Trata-se, portanto, de uma mesma lógica não dualista. Assim como não se reconhece um dualismo entre palavra e ação, organismo biológico e cultura; para pensar o espaço, este também não pode ser restrito ao local onde acontece, mas sim, à constituição de subjetividades e afetos que engendra.

A partir dessas fundamentações teóricas, a proposta desse artigo é analisar três exemplos de experiências performativas que problematizaram a questão da violência contra mulheres, partindo especificamente da criação de territorialidades. Ao pensar dramaturgias para constituir esferas públicas de atuação e criar redes de comunicação, tais experiências instauraram o que os filósofos Gilles Deleuze e Félix Guattari definiram como territorialidades. Este conceito, ao lado de todos os outros mencionados anteriormente, como os de esfera pública e performatividade, emerge de estudos que analisam a relação entre corpo e ambiente na construção de subjetividades.

No caso específico de Deleuze e Guattari, as propostas para pensar o tema giram em torno do que chamaram de geofilosofia, formulada no livro o que é filosofia? (1992) e, antes disso, na pesquisa que desenvolveram em torno do ensaio sobre capitalismo e esquizofrenia, que integra a obra Mil Platôs (1995).

Em linhas gerais, pode-se dizer que a territorialidade não demarca apenas um território ou local, mas sim, um campo de conexões, relações múltiplas e devires que estabelecem, por sua vez, regimes de troca, captura e desestabilização de códigos dados.

No que se refere às artistas que vamos analisar, ao configurar um espaço de ação, elas criaram movimentos e ativaram dinamicidades ao suposto território demarcado pela experiência artística, acionando sucessivas territorializações e desterritorializações, para questionar as relações de poder que transitam entre 
público e privado, fronteiras de gêneros e limites entre arte e vida. São elas: Tânia Bruguera (Cuba), Martha Araújo (Brasil) e o coletivo Polvo de Gallina Negra (México).

\section{Criar junto em nome da Liberdade}

Polvo de Gallina Preta (black hen powder) foi o primeiro coletivo feminista do México concebido desde o início apenas por artistas mulheres. As fundadoras foram Monica Mayer e Maris Bustamante. Em 1983, ano da fundação do grupo, contaram com a participação da fotógrafa Hermínia Dosal, que continua muito atuante, até hoje, mas teve breve participação no coletivo.

No site do coletivo ${ }^{3}$, as artistas diziam-se frustradas com o sistema patriarcal e sexista e, para expressar suas principais indagações, decidiram criar o coletivo para convocar outras artistas a opinar livremente sobre os principais problemas que enfrentavam, tendo em vista mudar a forma com que as mulheres eram vistas nos meios de comunicação de massa, as suas imagens na sociedade e assim por diante. Pode-se considerar que as performers buscavam problematizar a ausência notável das mulheres mexicanas nas macropolíticas, ou seja, em instituições, no mercado de trabalho formal e no governo.

O nome do coletivo Polvo de Gallina Preta refere-se a um pó de cor preta, extremamente barato, e que pode ser encontrado em todos os mercados tradicionais do México. A sua função primordial é evitar o mau olhado. Como sempre foi associado à bruxaria, as artistas imaginaram que poderia ser uma forma de proteger as mulheres - principalmente as artistas e feministas - contra a mágica patriarcal que fazia com que todas elas desaparecessem. Para cada uma das diversas manifestações artísticas feministas criavam uma espécie de subtítulo como, por exemplo, "Polvo de Gallina Preta: Receitas para colocar mau olhado em estuprador".

Pode-se afirmar que uma das grandes questões propostas por este coletivo, refere-se ainda ao desaparecimento simbólico de muitas mulheres, que, mesmo

${ }^{3}$ Disponível em: http://www.pintomiraya.com/pmr/gallina-negra. Acesso em: 17 abr. 2020. 
estando presentes, é como se estivessem invisíveis ou sem voz. Imbuídas de sua magia performativa, as artistas viajaram por muitos locais, no México e redondezas, muitas vezes sem recursos, palestrando para pouquíssimas pessoas, em auditórios esvaziados. Além das dificuldades de ordem prática, relatam que sofreram assédio de homens, inclusive entre colegas artistas, e sempre foram agressivamente questionadas pela forma como, muitas vezes, apresentaram-se nuas.

Mais uma vez, não se tratava de lidar com literalidades. A nudez do corpo significava a atitude de se expor, de estar em cena escancarada de modo a construir em movimento, o que Michel Foucault chamava de constituição de si Isso porque, assim como propõe Foucault, nunca se tratou de simplesmente criar uma narrativa confessional, mas, neste caso, de lá estar, fazendo da presença nua um manifesto potente para criar outras territorialidades, dentro e fora do corpo. Assim, a constituição das performers como sujeitos, seria sempre, de algum modo, coletiva e compartilhada nos ambientes que escolheram ativar. Em Foucault nunca houve uma essencialidade do sujeito, uma verdade inalienável, mas sim, uma construção inevitavelmente política e afetada pelos contextos de subjetividade que constituem os sujeitos. Assim, mesmo em situação de sujeição (política), os sujeitos se constituem e produzem subjetividades.

Neste sentido, apesar de todas as resistências, Mayer e Bustamante trabalharam ativamente por dez anos (1983-1993), promovendo aparições em jornais, revistas, e propondo cerca de vinte e oito projetos, sem contar com nenhum apoio, mas insistindo na afirmação de suas subjetividades e na potência do coletivo.

Um bom exemplo foi a obra ¡MADRES!. Concebida em 1987, esta performance/projeto de longa duração ocupou uma parte do Museu Carrillo Gil na Cidade do México, com Tres Madres para un Desmadre e a Sociedade de

4 O tema da escrita e constituição de si aparece em diversos livros de Foucault, especialmente aqueles que se dedicam a pensar a constituição do sujeito. O ensaio "A escrita de si; O uso dos prazeres e as técnicas de si” está incluído em Ética, Sexualidade, Política. Col. Ditos e escritos (2004). Outras publicações relevantes para o tema são: História da Sexualidade III, o cuidado de si (1985); Hermenêutica do Sujeito (2004); O Governo de si e dos Outros (2010); e A Coragem da Verdade (2011). 
Espetáculos na Colônia Navarte em 1990, entre outros.

O tema proposto, como sugere o próprio título do projeto, era a maternidade. Assim, a ação inaugural deste experimento foi engravidar. No primeiro momento, as performers Meyer e Bustamante tiveram um filho com seus respectivos companheiros, com uma pequena diferença de idade de três meses.

Na segunda fase do projeto, convidaram dez homens para ser "mãe por um dia" e participar de uma ação em que eles escreveriam cartas para suas mães dizendo tudo que eles sempre tiveram vontade de dizer mas, até então, faltara coragem. Durante esse período, aconteceram diversas intervenções performáticas que apresentavam as complexas relações afetivas. Em 1991, promoveram uma performance em uma manifestação de rua na cidade do México sobre maternidade voluntária.

Em 1987, as performers foram entrevistadas no programa televisivo de Guillermo Ochoa5 e "reencenaram" uma parte de performance de "Madre por un día”, usado pelo coletivo como parte de suas experimentações e ações performáticas. Bustamante afirma que as condições para uma mulher viver no México ainda são muito adversas, e por isso sempre estão em constante luta para viver. As mulheres sempre foram excluídas da sociedade somente por serem mulheres e relegadas exclusivamente ao papel de mães.

Este programa televisivo acabou se tornando um marco no trabalho do coletivo. Por conta da grande audiência, tiveram a oportunidade de compartilhar uma performance para questionar o papel do homem mexicano. A presença do jornalista Guillermo Ochoa que acompanhou a ação e era, explicitamente contrário ao debate, acabou transformando a performance em um manifesto político. ${ }^{6}$

Há pouco material disponível sobre Polvo de Gallina Preta, apesar da atuação do coletivo por uma década, o que infelizmente representa a atualidade das

${ }^{5}$ Performance no programa de Guillermo Ochoa durante seu programa Nestor Mundo no Canal 2. disponível em: https://www.youtube.com/watch?v=abaDXr3HKck

${ }^{6}$ É importante salientar que o movimento feminista não aconteceu da mesma forma em todos os países. No México, só começa nos anos 1970, influenciado pelas manifestações estudantis de 1968. Daí a dificuldade sentida até hoje para afirmar o protagonismo das mulheres. 
questões propostas pelas artistas, elas próprias relegadas ao desaparecimento. No entanto, o fato de terem acionado territorialidades simbólicas a partir de suas performances, ativou algumas redes. Um exemplo destas territorialidades simbólicas seria a presença das mães fora do ambiente doméstico e a dos pais com os filhos em casa. Arquetipicamente, em vários contextos culturais, considera-se o feminino restrito ao âmbito doméstico e o masculino como pertencente ao trabalho externo. A abertura à possibilidade de um atravessamento de fronteiras, proposta por "Madre por un día”, criou o que identificamos como novas territorialidades simbólicas que desafiam as compartimentações espaciais e, ao mesmo tempo, as relações de poder.

Como explica a autora Villegas Morales, este coletivo foi fundamental na história da arte feminista mexicana, inclusive por ter optado, muitas vezes, pelo uso do humor e do chiste para enfrentar a violência masculina. De certa forma, o Polvo de Gallina Preta abriu caminhos para debates, até então, praticamente inexistentes no contexto artístico mexicano. Após o encerramento das suas atividades, surgiram muitos outros grupos que fortaleceram a cena artística feminista local como, por exemplo, o Tlacuilas y Retrateras (1983-1984) integrado por Ruth Albore, Consuelo Almeda, Karen Cordero, Ana Victoria Jiménez, Lorena Loaiza, Nicola Coleby, Marcela Ramírez, Isabel Restrepo, Patricia Torres, Elizabeth Valenzuelay e Monica Mayer, cujo projeto mais importante foi La Fiesta de Quince Años (1984); e o Bio-arte (1983-1984), formado por Guadalupe García, Laita Rose Van Lengen, Roselle Faure e Nunik Sauret.

\section{A arte útil em busca de novas territorialidades}

Outra experiência que aciona a arte feminista no contexto da América Latina a partir da criação de territorialidades, é a de Tania Bruguera, uma artista cubana que explora em seus trabalhos as relações entre ativismo, arte, performance, mudanças sociais e poder governamental, político e econômico. Suas primeiras obras focavam em seu próprio corpo, explorando aí a abertura de trilhas afetivas, como nas performances de 1985, nas quais homenageou a sua conterrânea Ana 
Mendieta?

No decorrer de sua extensa obra, Bruguera passou a utilizar a performance para problematizar e questionar as realidades políticas que considerava mascaradas pelo Estado, a partir de atos de censura sobre veículos midiáticos de grande alcance controlados após a Revolução Cubana. No final de 2013, preocupada com a necessidade de reafirmar a potência transformadora da arte, a artista propõe o conceito de Arte Útil ${ }^{8}$, sugerindo que a arte fosse vista como uma ferramenta para que as intervenções artísticas, como táticas de ativação sociais e políticas aptas a mudar a forma como a sociedade se organiza.

Este projeto foi atrelado à Escola de Arte Útil, cujo objetivo é propor novas formas de pensar a arte, a fim de adentrar espaços urgentes dentro das instituições. O arquivo gerado a partir dessas ações, constitui-se como a reunião de diversos artistas que propõem trabalhos em conjunto com Bruguera, acionando territorialidades, performances e ações de longa duração. A sua proposta tem sido a de enfatizar processos afetivos, sociais e políticos de modo a ressignificar a arte, buscando novos usos.

Entre 2010 e 2016, o número de dissidências arbitrárias em Cuba, aumentou significativamente. O governo passou a controlar ostensivamente as ações da população. As detenções passam a ocorrer sem nenhuma justificativa, somente para evitar aglomerações e discussões sobre política. Em 2018, a própria Bruguera foi presa por protestar contra o decreto 349 o qual previa restringir as expressões artísticas que não fossem aprovadas pelo governo cubano. De acordo

\footnotetext{
Bruguera no período entre 1985 a 1996 fez uma série em homenagem a Ana Mendieta, que recebeu e acolheu Bruguera quando ela era adolescente e imigrou aos Estados Unidos. Então, a artista reencenou algumas performances de Mendieta durante alguns anos. Na época foi uma reação ao momento político da época. http://www.taniabruguera.com/cms/495-0-Tribute+to+Ana+Mendieta.htm

Ana Mendieta (1948-1985), nascida em Havana, foi escultora, performer, vídeo artista e pintora. Em 1961 migra para Nova Iorque, a obra de Mendieta geralmente era autobiográfica e focava nas questões do feminismo, morte, vida, lugar de pertencimento e violência. Além de estar sempre conectada com os elementos da terra e sua conexão física e espiritual.

${ }^{8}$ A associação de arte útil é uma plataforma para conhecer e trocar, bem como compartilhar ideias, e a partir disso desdobra-se em uma escola que possui um trabalho artístico. Em 2019 em parceria com a Pinacoteca de São Paulo, promoveu um ciclo de workshops que somam a esta ideia. http://pinacoteca.org.br/artistas/tania-bruguera/

Aqui também disponibilizo o site do museu de arte útil que a artista construiu https://museumarteutil.net/archive/
} 
com o decreto assinado pelo presidente Miguel Díaz-Canel, os artistas não podiam fornecer serviços artísticos, e quem contratar e pagar por estes serviços estará sujeito a sanções, desta forma o controle das obras poderia vir do Estado, e apenas com o seu crivo, as obras poderiam estar em circulação. ${ }^{9}$

Uma de suas obras mais conhecidas é Tatlin's Whisper \#6 (Havana Version), apresentada em 2009 na Bienal de Havana. ${ }^{10}$ A peça consistia em um galpão no qual o microfone ficava aberto para pessoas se manifestarem por dez minutos, sem qualquer censura, até serem escoltadas para fora do palco por uma pessoa vestida com uniformes militares. A tentativa de Bruguera de reencenar essa performance em Havana, suscitou múltiplas prisões em 2014 e 2015.

Após estes episódios, a artista observou que o papel da arte em países socialistas é bastante singular, pois nestes cenários políticos a arte tem de fato como função abrir espaços de liberdade, a despeito de toda opressão. Seguir existindo artisticamente, já é uma forma de resistência política.

Apesar de ter iniciado sua pesquisa investigando o próprio corpo, sempre buscou o contato com o público, criando ações para construir territorialidades comuns. Assim, buscou conceber cenas que deixam de ser apenas uma expressão de si mesma, para conceber o que Eleonora Fabião chama de programa performativo, inspirada pelo modo como Deleuze e Guattari conceituaram no ensaio "Como criar para si um Corpo sem Órgãos” (1999). Fabião ancorada no pensamento dos filósofos, sugere que este programa torna-se um "motor de experimentação" equivalente ao momento em que o corpo cria uma relação de corpos e ativa um circuito de afetos. Seria o desencadeamento de questões referentes a uma espécie de pertencimento. Segundo a autora: “O programa é o enunciado da performance: um conjunto de ações previamente estipuladas, claramente articuladas e conceitualmente polidas a ser realizado pelo artista, pelo

\footnotetext{
${ }^{9}$ A questão do número de dissidências arbitrárias em Cuba foi amplamente discutida na imprensa, inclusive no Brasil, em edições da Globo G1(http://g1.globo.com/mundo/noticia/2016/03/cuba-tem-presos-politicosa-pergunta-que-incomodou-raul-castro-durante-visita-de-obama.html) e da revista Exame (https://exame.com/mundo/dissidencia-denuncia-aumento-de-detencoes-em-cuba/). O site Human Rights Watch atualizou estes dados em relatórios de 2019, disponíveis em: https://www.hrw.org/pt/worldreport/2019/country-chapters/325505. Acesso em: 9 jul. 2020.
}

10 Performance disponível em: https://www.youtube.com/watch?v=B3KOV26APLM Acesso em: 9 abr. 2020. 
público ou por ambos sem ensaio prévio" (Fabião, 2013, p.4). O “corpo sem órgãos" é antes de mais nada um conjunto de práticas, um corpo sem determinação prévia, é a plena expressão do desejo, uma série de atos-experimentações. Fabião conclui que este conceito soma ao corpo performativo, que é composto de atos que oscilam entre a cena e a não cena, é a vibração que cria-se. (Fabião, 2013, p.6).

Abre-se, assim, a possibilidade para que o público também constitua a cena. Rompe-se a fronteira entre arte e vida, pois é o público - e não apenas o artista que norteia e move todo percurso a experimentação. Esta hipótese de Fabião cabe perfeitamente para o caso específico da performance de Bruguera. Durante a ação de abrir o microfone às pessoas comuns (propositalmente anônimas), uma pomba branca era colocada gentilmente no ombro de cada participante que ia fazer sua fala, em alusão a pomba que pousou no ombro de Fidel Castro durante seu primeiro discurso em Havana em 1959 após o triunfo da revolução. Bruguera, reafirma uma estratégia usada por outros artistas e ativistas como o Comitê Invisível, especialmente no livro Aos nossos amigos, crise e insurreição (2015), cujo ponto de partida é não se deixar governar nem querer governar, desertando das matrizes arraigadas de poder, sem se deixar impregnar pela lógica do adversário, neste caso, os aparelhamentos do Estado. O objetivo é, portanto, estimular os participantes de forma a vislumbrar a possibilidade de recontextualizar o passado, confrontando sobretudo a apatia que se espalhou diante de uma revolução social que impactou negativamente a situação das mulheres. ${ }^{11}$

Neste sentido, não raramente, o direito ao simples aparecimento nos espaços públicos, já constitui por si só e, em diversos aspectos, uma revolução. Em 2019, em uma entrevista para revista Época, Bruguera explicou que, quanto mais ocupava os espaços com sua arte e seu corpo, mais a repressão policial acontecia: "Sigo fazendo minha arte e tento exigir dela o mesmo que exijo da política: que

\footnotetext{
${ }^{11}$ Em um artigo publicado pela revista Medium em 2019, (https://medium.com/qg-feminista/a-questão-dasmulheres-em-cuba-1d1a792a8ec7) evidencia-se que não existe um marco específico em Cuba sobre o início do movimento feminista, apesar de muitas mulheres terem demonstrado resistência ao sistema patriarcal dominante, promovendo movimentos sociais que discutem, produzem materiais e campanhas que combatem a violência contra mulher, e problematizam os abusos cotidianos.
} 
transgrida." ${ }^{\prime 2}$

A chave de seu processo está, portanto, em criar territorialidades subversivas para questionar limites e fronteiras em uma multiplicidade de sentidos: políticos, artísticos, sexuais e econômicos. No seu caso, tais territorialidades são ainda mais ampliadas na medida em que lidam com ensino (Escola de Arte Útil) e documentação (arquivo digital), tornando estas experiências fundamentais no contexto cubano e muito além dele.

\section{Um corpo e suas impossibilidades}

A performer, artista plástica e escultora Martha Araújo começa a performar em 1980, sem saber exatamente que esse era o termo escolhido para o tipo de arte que a interessava. Até fazer parte do acervo do Hammer Museum ${ }^{13} \mathrm{em}$ Los Angeles, nos Estados Unidos, a sua obra foi lançada ao esquecimento, tanto no Brasil, como internacionalmente. Em 2017, integrou a exposição Radical Women: Latin American Art 1960-1985, exibida um ano depois em Nova Iorque no Brooklyn Museum ${ }^{14}$ e, logo em seguida, na Pinacoteca15 de São Paulo com o mesmo título (Mulheres Radicais: arte latino-americana 1960-1985).

Os processos de criação de Araújo começam durante a ditadura militar brasileira (1964-1985), o que a leva à prisão, como tantas outras artistas e ativistas. A partir disso, torna-se fundamental que comece a criar seus "objetos performáticos"; tecidos e esculturas que questionam os limites entre o corpo livre e aprisionado.

Um dos grandes exemplos data de 1985, quando a artista cria a instalação

12 Disponível em: https://epoca.globo.com/aqueles-que-governam-baseados-no-medo-se-valem-de-ideiasretrogradas-diz-tania-bruguera-23376352 Acesso em: 15 jun. 2020.

${ }^{13}$ Disponível em: https://hammer.ucla.edu/radical-women Acesso em: 15 jun. 2020.

${ }^{14}$ Disponível em: https://www.brooklynmuseum.org/exhibitions/radical_women Acesso em: 15 jun. 2020.

${ }^{15}$ Disponível em: https://pinacoteca.org.br/programacao/mulheres-radicais-arte-latino-americana-1960-1985/ Acesso em: 27 abr. 2020. 
"Para um corpo e suas possibilidades", exibida na Galeria Jaqueline Martins"16 em São Paulo.

Nesta instalação, Araújo disponibiliza macacões cobertos de velcro para que o público se junte à ação. A escolha deste material para compor os macacões, deveu-se ao fato de que o material representava a adesão e a separação. A ação começa com os participantes escorregando por rampas (como pistas de skate), até ficarem presos. A partir de então, o único modo de se libertar é através do movimento. Quanto mais pessoas se aglomeram, mais difícil separar os corpos que precisam lutar por suas próprias liberdades. Em um texto distribuído durante a exposição e publicado no jornal O Globo, a artista fala sobre a sua motivação diante da obra, e explica que sempre quis se amarrar a alguém e se libertar só para sentir a sensação de estar livre:

Primeiro construí um cinto e dois braceletes com ímãs. O objetivo era prender os pulsos no cinto, mas notei que não prendiam o suficiente. Eu queria algo que prendesse mais, para que fosse possível sentir uma sensação de libertação mais forte, pois quanto mais preso você fica, maior a sensação de liberdade ao se soltar. Um dia, tirei a pulseira e descobri que o velcro que a fechava tinha o poder que eu queria [...]. Fiz macacões aos pares, um com um lado do velcro e o segundo com o outro lado, de maneira que um macacão colava no seu par e, ao descolá-lo ouvia-se um som de rasga-pele muito forte..$^{17}$

Por conseguinte, pode-se observar que Araújo utiliza o corpo como uma forma de ativação do eu e do outro, lidando com as relações e expressões corporais como um reflexo do mundo. De fato, a ação só acontece quando o público se conecta e experimenta o compartilhamento de corpos.

A exemplo de outras artistas que já haviam começado a testar performances a partir da percepção do corpo coletivo ${ }^{18}$, Araújo promove um exercício sensorial que é uma forma

${ }^{16}$ Disponível em: http://moussemagazine.it/martha-araujo-jaqueline-martins-2015/ Acesso em: 28 abr. 2020.

${ }^{17}$ Disponível em: https://casavogue.globo.com/Colunas/Gemada/noticia/2015/03/role-artsy-jaime-lauriano-emartha-araujo.html Acesso em: 28 abr. 2020.

18 Um dos exemplos mais conhecidos é Lygia Clark (1920-1988), especialmente sua série Bichos e as obras Canibalismo e Baba Antropofágica, ambas de 1973, entre muitas outras. Clark é conhecida como uma das pioneiras da body art e instalações, na história da arte e da performance no Brasil. 
fenomenológica de conhecimento e apreensão, para fazer de si o fazer do outro, questionando os modos os quais o mundo se organiza e as possibilidades de um fazer junto.

Ao evocar assim, corpo e suas territorialidades, os experimentos ocorrem na medida em que recriam e remodelam linguagens e processos para ocupar territórios menos opressivos, recusando os aprisionamentos corporais, tanto em seu aspecto factual, como simbólico.

\section{De que territorialidade está se falando?}

As performances das artistas Bruguera, Araújo, Bustamante e Meyer podem ser vistas, cada qual a seu modo, como convocações de corpos políticos, que partem de diversas vulnerabilidades e memórias de repressão, como uma forma de ativar novas possibilidades de vida, a partir da criação de territorialidades.

É importante lembrar que feminismo e violência contra mulheres na América Latina são tópicos polêmicos há muitas décadas, mas os números continuam assustadores. De acordo com um relatório da ONU, publicado no jornal El Pais em novembro de 2018, a América Latina e América Central são as regiões do mundo, fora de zonas de guerra, com maior índice de feminicídio ${ }^{19}$.

Com o advento da pandemia de Covid-19, esses números aumentaram ainda mais. No caso específico do Brasil, a Lei Maria da Penha, em vigor desde 2006, ajudou a combater a impunidade, até então imperante, no entanto, a exemplo de outros países vizinhos, as denúncias ainda são poucas em relação aos números reais de violência contra mulheres e as estatísticas de mortes provavelmente se referem, como indica a reportagem, apenas a uma ponta do iceberg.

Além da imprensa, há documentações e debates em torno da violência contra mulheres em várias áreas acadêmicas de conhecimento, voltadas especificamente aos estudos gênero, à sociologia, ao direito, à história, à psicologia e assim por diante. No entanto, os debates sobre o modo como a arte lida com a violência e pode denunciá-la, documentá-la e questioná-la são bem mais recentes. Uma das experiências pioneiras, neste sentido, foi lançada pelo Instituto Hemisférico de Performance e Política, criado em

${ }^{19}$ Disponível em: https://brasil.elpais.com/brasil/2018/11/24/actualidad/1543075049_751281.html Acesso em: 13 de junho 2020. 
1998, na New York University pela professora Diana Taylor ${ }^{20}$. Embora não seja voltado exclusivamente aos estudos da violência contra mulheres, o Hemi - como é conhecido por seus participantes - busca criar um modelo anticolonial para lidar com performances sem se ater a dicotomias do tipo norte e sul, homem e mulher, teoria e prática, e assim por diante. A partir dos encontros, publicações, palestras e workshops que promove, a performance deixou de ser considerada apenas uma ilustração ou representação de temas, sendo reconhecida como propositora de debates, nos quais, explicitam-se as relações de poder.

Autoras como Judith Butler, entre outras citadas no início deste artigo, sempre estiveram atentas às formas coletivas de manifestações políticas e a como esses corpos ativam ações performativas com o intuito de ocupar territórios.

As coligações que constituem corpos políticos mobilizam formas de resistência, seja como manifestações urbanas, vigílias, passeatas em espaços públicos, ou como performances artísticas. O que buscamos demonstrar neste artigo é, justamente, o papel fundamental das performances artísticas nas lutas feministas. A contrário do que afirmam autoridades mais conservadoras, as performances são muito mais do que mero entretenimento, ampliando as possibilidades de resistência através da criação de territorialidades. ${ }^{21}$

No caso do coletivo Polvo de Gallina Negra, a maternidade, por exemplo, transformou-se na abertura de uma territorialidade subjetiva para atravessar fronteiras referentes à divisão de trabalho, desafiando a tradicional compartimentação de gêneros. Na proposta de Bruguera, vozes silenciadas encontram, finalmente, espaço de emissão, conferindo existência a narrativas até então confinadas em contextos invisíveis. E nos experimentos de Martha Araújo, a territorialidade emerge da possibilidade de fazer junto, de compartilhar desejos e percepções, testando exercícios de liberdade a partir do movimento corporal individual e coletivo.

De acordo com Butler, a vulnerabilidade não é apenas apatia, vitimização e paralisia, mas "modos de expressar e demonstrar a condição precária que engaja de maneira

\footnotetext{
20 Disponível em: https://hemisphericinstitute.org/pt/mission. Acesso em: 3 de junho 2020

${ }^{21}$ Para a maioria dos governos antidemocráticos, a arte e a educação costumam ser negligenciadas, como áreas de menor interesse em relação a outros setores cuja relevância econômica parece mais significativa. Performances artísticas são particularmente negligenciadas e consideradas como mero entretenimento para circuitos muito particulares. A este respeito, vale consultar a obra Nas Ruínas do Neoliberalismo: a Ascensão Antidemocrática no Ocidente, de Wendy Brown (2019).
} 
importante ações corpóreas e formas de liberdade expressiva que pertencem propriamente a assembleia pública" (2018, p.16). Esta é também a maneira de agir/imaginar das artistas aqui apresentadas. Como vimos, cada qual explicitou uma aptidão singular para gerar suas próprias assembleias.

Butler explica que as assembleias podem desafiar o capitalismo, os sistemas neoliberais, as desigualdades sociais, os danos ecológicos, os sistemas militares, os direitos das mulheres, o direito de ocupação da esfera pública, a cidadania e, até mesmo, os direitos humanos em geral. Seja qual for o caso, é sempre possível identificar o direito performativo e plural de aparecimento e, quando as devidas condições para agir não existem, são as ações performativas que criam estas condições e suas novas territorialidades.

Em síntese, pode-se considerar que assembleias são maneiras de convocar e invocar corpos vivos que, por mais vulneráveis que sejam, cultivam o ativismo, abrindo possibilidades para pensar e agir de modos não convencionais: "[...] a liberdade de assembleia pode ser considerada um retorno ao direito de revolução." (Butler, 2018, p.177).

Neste sentido, além dos aspectos já mencionados anteriormente, as experiências das artistas aqui apresentadas, elucidam algo que também tem norteado inúmeros debates filosóficos, especialmente, quando se observa a coexistência e a criação do comum como alternativa ética e social de responsabilização. No caso das assembleias, estas seriam versões emergentes e provisórias de uma possível soberania popular. Assim, existir junto na praça pública, compartilhar um microfone, expor o corpo coletivamente ou se aglomerar em macacões com velcro são, ao mesmo tempo, metáforas de um mundo imaginado e ações que, efetivamente, podem constituir um corpo comum.

A chave parece estar na potência de criar junto, uma das aptidões com as quais a arte e, particularmente, a arte da performance tem ativado com grande interesse em busca de novos sentidos para a vida. Talvez, o grande desafio das ações performativas de mulheres que buscam a assembleia como ignição para a criação - especialmente nos contextos latino-americanos - seja, justamente, a de escavar esses espaços de compartilhamento, desafiando um dos mais valorizados pressupostos do sistema capitalista: a propriedade privada e o foco nas necessidades exclusivamente individuais. 


\section{Referências}

AUSTIN, John. How to do things with words. Boston: Harvard University Press, 1962.

BROWN, Wendy Nas ruínas do neoliberalismo, a ascensão da política antidemocrática no Ocidente, trad. Mario Antunes Marino. São Paulo: Ed. Politéia, 2019.

BUTLER, Judith. Gender Trouble, Feminism and the Subversion of Identity. New York: Routledge, 1990.

BUTLER, Judith. Corpos em aliança e a política das ruas, notas para uma teoria performativa da assembleia. trad. Fernanda Siqueira Miguens. Rio de Janeiro: Civilização Brasileira, 2018.

COHEN, Renato. Work in Progress na cena contemporânea, criação, encenação e recepção. São Paulo: Perspectiva, 1998.

COMITÊ INVISÍVEL Aos nossos amigos, crise e insurreição, trad. Edições Antipáticas. São Paulo: n-1 edições, 2015.

DELEUZE, Gilles; GUATTARI, Félix. O que é filosofia? trad. Bento Prado Jr e Alberto Allonso Munhoz. São Paulo: Editora 34, 1992.

DELEUZE, Gilles; GUATTARI, Félix. Mil Platôs, Capitalismo e Esquizofrenia. Volume 1, (trad) Aurelio Guerra Neto e Celia Pinto Costa. São Paulo: Editora 34, 1995.

DELEUZE, Gilles; GUATTARI, Félix. "Como criar para si um Corpo sem Órgãos". In: Mil Platôs. Vol.3. trad. Aurélio Guerra Neto. São Paulo: Editora 34, 1999.

Fabião, Eleonora. Programa Performativo: o corpo-em-experiência. Revista do LUME, núcleo interdisciplinar de pesquisas teatrais da UNICAMP. Número 4, dezembro de 2013.

FOUCAULT, Michel. História da sexualidade /II - O cuidado de si. Rio de Janeiro: Graal, 1985.

FOUCAULT, Michel. Hermenêutica do Sujeito. São Paulo: Martins Fontes, 2004

FOUCAULT, Michel. "A escrita de si; O uso dos prazeres e as técnicas de si". In: Ética, Sexualidade, Política. Col. Ditos e escritos. Rio de Janeiro: Forense Universitária, 2004.

FOUCAULT, Michel. O Governo de si e dos Outros. São Paulo: Martins Fontes, 2010 
FOUCAULT, Michel. A Coragem da Verdade. São Paulo: Martins Fontes, 2011

GLUSBERG, Jorge. Linguagem da performance. trad. Renato Cohen. São Paulo: Perspectiva, 2013.

MORALES, Villegas Gladys. Los grupos de Arte Feminista en México. Repositório Digital de la Universidad Veracruzana. Mexico, 2006.

PAIS, Ana. (Org.) Performance na Esfera Publica. Lisboa: Orfeu Negro, 2017.

PHELAN, Peggy. Unmarked, the politics of performance. New York: Routledge, 1993.

SCHNEIDER, Rebecca. Performing Remains, Art and War in Times of Theatrical Reenactment. New York: Routledge, 2011.

Recebido em: 28/06/2020

Aprovado em: 29/07/2020 